\title{
Association between glycemic control and risk of venous thromboembolism in diabetic patients: a nested case-control study
}

Sarah H. R. Charlier ${ }^{1,2}$, Christian Meier ${ }^{3}$, Susan S. Jick ${ }^{4,5}$, Christoph R. Meier ${ }^{1,2,4^{*}}$ and Claudia Becker ${ }^{1,2}$

\begin{abstract}
Background: Previous studies suggested an elevated risk of venous thromboembolism (VTE) among patients with type 2 diabetes mellitus (T2DM), with a possible sex difference. The impact of glycemic control on the risk of VTE is unclear. Our objective was to analyze the association between glycemic control and the risk of unprovoked (idiopathic) VTE in men and women with T2DM.

Methods: We conducted a nested case-control analysis (1:4 matching) within a cohort of patients with incident T2DM between 1995 and 2019 using data from the CPRD GOLD. We excluded patients with known risk factors for VTE prior to onset of DM. Cases were T2DM patients with an unprovoked treated VTE. The exposure of interest was glycemic control measured as $\mathrm{HbA} 1 \mathrm{c}$ levels. We conducted conditional logistic regression analyses adjusted for several confounders.
\end{abstract}

Results: We identified 2'653 VTE cases and 10'612 controls (53.1\% females). We found no association between the $\mathrm{HbA} 1 \mathrm{c}$ level and the risk of VTE in our analyses. However, when the most recent $\mathrm{HbA1c}$ value was recorded within 90 days before the index date, women with $\mathrm{HbA1}$ c levels $>7.0 \%$ had a $36-55 \%$ increased relative risk of VTE when compared to women with $\mathrm{HbA} 1 \mathrm{c}>6.5-7.0 \%$.

Conclusions: Our study raises the possibility that female T2DM patients with $\mathrm{HbA1}$ c levels $>7 \%$ may have a slightly higher risk for unprovoked VTE compared to women with HbA1c levels $>6.5-7.0 \%$. This increase may not be causal and may reflect differences in life style or other characteristics. We observed no effect of glycemic control on the risk of VTE in men.

Keywords: Diabetes mellitus type 2, Venous thromboembolism, VTE, Glycemic control, HbA1c, Sex, Case-control study

\section{Introduction}

Diabetes mellitus (DM) is a chronic disease with a high global prevalence, affecting some 450 million (8.8\%) patients worldwide and causing approximately 5 million deaths per year [1]. In the UK, 4.7 million patients (7.0\%)

\footnotetext{
*Correspondence: christoph.meier@unibas.ch

${ }^{1}$ Basel Pharmacoepidemiology Unit, Division of Clinical Pharmacy

and Epidemiology, Department of Pharmaceutical Sciences, University

of Basel, Spitalstrasse 26, 4056 Basel, Switzerland

Full list of author information is available at the end of the article
}

had diagnosed or undiagnosed DM in 2019 [2]. Because the majority (90\%) of the cases are DM type 2 (T2DM) [2], T2DM and its complications are of great importance for the health system [1]. T2DM is characterized by hyperglycemia due to insulin deficiency and insulin resistance, and it is linked to an increased risk for several cardiovascular diseases [3, 4].

While it has been shown that T2DM patients have a higher risk for arterial thrombosis, the association between T2DM and the risk of venous thromboembolism (VTE) has been studied less. VTE, a medical 
condition in which a thrombus forms in the venous system, can manifest as deep vein thrombosis (DVT) or as pulmonary embolism (PE), if the thrombus travels to the pulmonary arteries [5-7]. VTE is associated with a high mortality $[5,8]$. Its prevention and management is a priority for the NHS, the National Health Service of the UK [9]. Unprovoked VTE [5] occurs at an incidence of 62.1 per $100^{\prime} 000$ person years [10]. However, especially at older ages ( $>60$ years), men have an approximately $20 \%-25 \%$ higher incidence rate of VTE than women [7, 11]. The term unprovoked is used in accordance with the definition provided by the NICE (National Institute for Health and Care Excellence) guideline on PE and DVT, meaning that-similar to the term idiopathic - no recent known major risk factors were present prior to the VTE [5].

Published findings regarding DM as an independent risk factor for VTE are not consistent $[6,12]$ However, it is well established that VTE occurs more than twice as often in patients with DM than in DM-free individuals $[13,14]$. Studies also show that men are at a higher risk for T2DM and VTE than women when both diseases are considered individually, while women are at higher risk of VTE once other comorbidities (such as DM, cardiovascular disease, and atherosclerosis) are involved $[12,15,16]$.

Since the degree of hyperglycemia is crucial in the development of DM-related complications [17, 18], the question arises whether there is also an association between hyperglycemia and the risk of VTE.

To date, recent studies assessing the impact of glycemic control on the risk of VTE in male and female patients with DM yielded conflicting results. While some authors found a statistically significant association between the level of glycemic control and the risk of VTE $[19,20]$, others did not [21]. In a population-based cohort study from Norway, the risk of VTE increased by $5 \%$ per one standard deviation increase in HbA1c. However, in this study, there were no HbA1c measurements available at a time point close to the VTE event [21]. None of the published studies analyzed the impact of glycemic control on the risk of VTE stratified by sex. However, the sex of the patient could not only have an impact on the development and progression of the disease itself [15, 22-24], but also on the association of glycemic control and risk of VTE.

A hypothesized pathway for an increased risk of VTE in patients with DM is that hyperglycemia contributes to elevated coagulation factors and impaired fibrinolysis $[4,13,25]$. A single unifying mechanism of DM complications might be hyperglycemia-induced overproduction of superoxide by the mitochondrial electron transport chain, which activates several damaging pathways [26]. The activation of these pathways causes additional intracellular oxidative stress, abnormalities of the gene expression of glomerular cells, hyperglycemiainduced cardiomyocyte dysfunction, and an increase of the enzyme GFAT (glutamine fructose- 6 phosphate amidotransferase), resulting in a variety of effects on gene expression and advanced glycation end product formation [26].

The objective of the present study was therefore to analyze the association between glycemic control and the risk of unprovoked VTE in patients with T2DM overall, as well as separately for men and women.

\section{Methods}

\section{Study design and data source}

We conducted a nested case-control analysis within a cohort of patients with incident T2DM between 01. January 1995 and 31. December 2019 in the UK-based primary care Clinical Practice Research Datalink (CPRD) GOLD.

CPRD GOLD contains anonymized medical records of over 11.3 million patients from more than 600 general practices in the UK. It is a governmental, non-profit database; the enrolled patients account for approximately $6.9 \%$ of the UK population. Patients within CPRD GOLD are representative of the UK general population with respect to age, sex, and ethnicity [27]. The database was established in 1987 and is a collaborative project between the National Institute for Health Research (NIHR) and the Medicines and Healthcare Regulatory Agency (MHRA). The information in the database comes from participating general practitioners (GPs), who are trained on recording medical information using standard software and coding systems. Medical diagnoses, referrals to specialists and secondary care settings, prescriptions, diagnostic testing, lifestyle information, and demographic data are all part of the recorded information [28]. Many validation studies have been performed that demonstrate the high quality of CPRD GOLD data [28-30]. The validity of the diagnoses of T2DM and VTE has been shown previously [31-33].

\section{Study population}

In order to ensure that we only included incident DM cases in the study population, patients had to have a minimum of 3 years of DM-free history in the database prior to onset. We identified patients based on specific codes for T2DM. We also included patients with an unspecific code for DM (e.g. general code for "diabetes") if they were older than 30 years at diagnosis and received an oral antidiabetic drug (OAD). Independently of age, if DM patients never received insulin, we classified them as T2DM patients. We used the onset of DM as the study entry date, defined as the date of the 
first recorded DM code or the date of the first prescription for a DM medication. If the prescription occurred more than 365 days prior to the first recording of a DM diagnosis code, we excluded the patient.

We excluded patients with a diagnosis of cancer (except non-melanoma skin cancer), alcoholism, or HIV at any time in the patient record to avoid substantial bias and confounding.

We excluded patients with a history of VTE (at any time prior to the diagnosis of T2DM), or a code for surgery, immobilization, trauma, paralysis and paresis, or use of HRT or the contraceptive pill within 3 months prior to the index date. We further excluded patients with a code for pregnancy or puerperium within 12 months prior to the index date.

\section{Case and control definition}

We defined cases as patients with a first-time recording of VTE during the study period, who received at least one prescription for an antithrombotic drug within 7 days prior until 90 days after the VTE [5, $34,35]$, including vitamin $\mathrm{K}$ antagonists, heparins, direct factor Xa inhibitors, direct thrombin inhibitors, fibrinolytic enzymes, or the synthetic penta-saccharide factor $\mathrm{Xa}$ inhibitor fondaparinux. The index date for each case was the date of the first recorded VTE. Since we excluded patients with known risk factors for a VTE prior to the outcome, we regard the VTE cases included in this study as having an unprovoked or idiopathic VTE [5].

We used risk set sampling to match each case to 4 controls from the study population, i.e. patients who did not experience a VTE between the onset of DM and the index date of their matched case. We matched controls to cases on age ( \pm 3 years), sex, general practice, index date (same index date as the case, and the control had to be present in the database on the index date), and T2DM duration ( \pm 365 days assessed by counting the days between the study entry date and the index date).

\section{Exposure definition}

The exposure of interest in this study was glycemic control after the onset of DM defined by HbA1c levels. We used the last recorded $\mathrm{HbA1c}$ value before the index date for our analyses. We assessed HbA1c levels in 7 categories: $\leq 6.5 \%(\leq 48 \mathrm{mmol} / \mathrm{mol}),>6.5-7.0 \%$ ( $>48-53 \mathrm{mmol} /$ $\mathrm{mol}$, reference group $),>7.0-7.5 \% \quad(>53-58 \mathrm{mmol} /$ $\mathrm{mol}),>7.5-8.0 \% \quad(>58-64 \quad \mathrm{mmol} / \mathrm{mol}),>8.0-9.0 \%$ (>64-75 mmol/mol), $>9.0 \%$ (>75 mmol/mol), and no HbA1c measurement. Results for patients with missing values were presented in a separate category.

\section{Statistical analysis}

We used conditional logistic regression to assess the association between levels of glycemic control (expressed as HbA1c levels) with HbA1c levels of $>6.5-7.0 \%$ $(>48-53 \mathrm{mmol} / \mathrm{mol})$ as the reference group and the risk of VTE, expressed as odds ratios (ORs) or adjusted ORs (aORs) with 95\% confidence intervals (CI). We also assessed the association between HbA1c level and the risk of VTE according to the patients' number of GP visits during the study period. Lastly, we conducted analyses in men and women separately.

We adjusted for the following comorbidities and comedications (recorded at any time in the patient record before the index date) in the final model based on previous clinical knowledge: BMI (categorical variable), smoking status (current, past, non-smokers, and unknown), CVD (including congestive heart failure, ischemic heart disease, myocardial infarction, hypertension, and stroke), osteoarthritis, use of insulin, bisphosphonates, systemic corticosteroids, low-dose acetylsalicylic acid, and current (last prescription within 30 before the index date) or past (last prescription $>30$ days prior to index date) use of metformin or sulfonylureas. We additionally tested for effect modification by obesity status (non-obese versus obese, defined as BMI levels $<30$ and $\geq 30$ ) of the association between level of HbA1c and risk of VTE.

In sensitivity analyses, we 1) restricted the sample to patients whose last $\mathrm{HbA1c}$ measurement was recorded within less than 90 days prior to the index date, 2) analyzed the risk of VTE separately for patients with a previous CVD diagnosis, and 3) conducted separate analyses of the risk of VTE by HbA1c levels for patient groups of different T2DM durations.

We conducted analyses using SAS software version 9.4 (SAS Institute, Inc., Cary, NC, USA).

\section{Results}

Within a cohort of $231^{\prime} 439$ patients with incident T2DM who fulfilled all study inclusion and exclusion criteria, we identified 2'653 T2DM patients with an incident VTE diagnosis and 10'612 matched control patients (Fig. 1).

Cases and controls were similar with respect to age and time from most recent $\mathrm{HbA} 1 \mathrm{C}$ value to index date. We observed a mean of $12.5 \mathrm{HbA} 1 \mathrm{c}$ measurements per case and $12.3 \mathrm{HbA} 1 \mathrm{c}$ measurements per control during the study period. The median time between the index date and the last HbA1c measurement was 117 days for cases and 116 for controls.

Patients exposed to insulin (aOR 1.63, 95\% CI 1.38-1.92) had an increased risk of VTE compared to never-users of insulin, independently of $\mathrm{HbA1c}$ levels. However, cases and controls who had at least one 


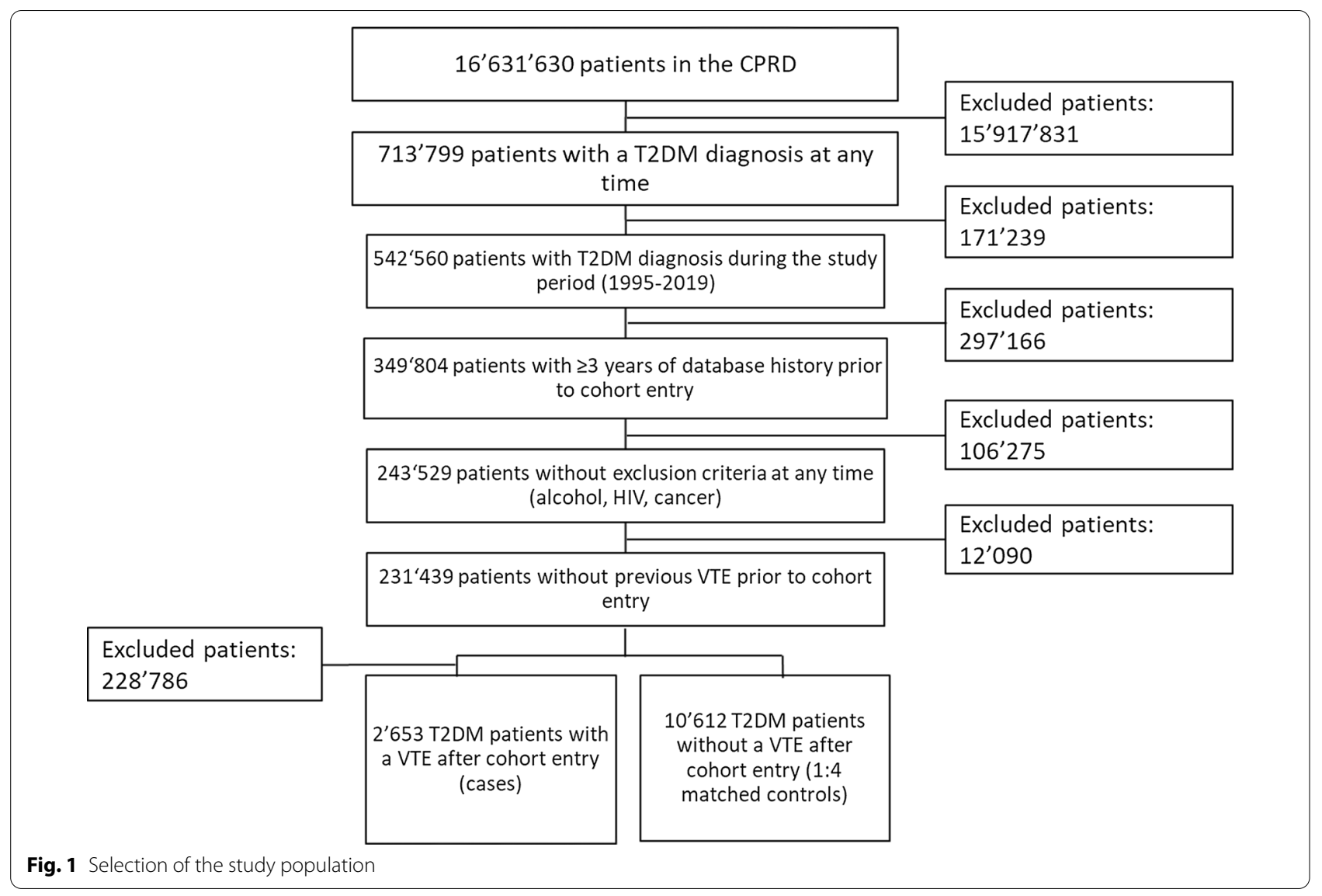

prescription for insulin also had longer mean T2DM duration than non-users of these drugs (approximately 4.2 years longer). We found no effect modification by $\mathrm{BMI}$ on the association between HbAlc level and the risk of VTE.

Table 1 provides information on the basic characteristics of cases and their matched controls at the index date.

We found no elevated relative risk for VTE in patients with the last HbA1c measurement $>7.0 \%$ ( $>53 \mathrm{mmol} /$ mol) compared to the reference group of patients with HbA1c levels $>6.5-7.0 \%(>48-53 \mathrm{mmol} / \mathrm{mol})$. The ORs for the various HbA1c categories are displayed in Table 2. There was no consistent linear increase in the risk of developing VTE with increasing HbA1c levels. Patients with missing HbA1c measurements had the highest risk of VTE (aOR 1.56, 95\% CI 1.29-1.88) when compared to patients with last HbA1c measurements of $>6.5-7.0 \%$ ( $>48-53 \mathrm{mmol} / \mathrm{mol}$ ) before the index date. Around one third of the cases with no HbA1c measurements $(8.4 \%$ in total) had little GP contact (0-14 GP visits: $34.7 \%$ $(\mathrm{n}=77), 15-29$ visits: $18.5 \%(\mathrm{n}=41)$, and $30+$ visits: $46.9 \%(n=104)$. We provide a separate table summarizing the characteristics of those patients without any HbA1c measurements as a Supplement.
When we stratified our analyses by sex (Table 2), we observed a slightly higher risk of VTE in women with HbA1c levels $>8.0 \%$ ( $>64 \mathrm{mmol} / \mathrm{mol}$ ) compared to the reference group of women with $\mathrm{HbA} 1 \mathrm{c}$ levels $>6.5-7.0 \%$ (>48-53 $\mathrm{mmol} / \mathrm{mol})$. There was no association between HbA1c levels and risk of VTE in men.

Among patients with preexisting CVD (Table 3), individuals with $\mathrm{HbA1c}$ levels $>7.0 \%$ (>53 $\mathrm{mmol} / \mathrm{mol})$ had a similar risk of VTE compared to patients with HbA1c levels between $>6.5-7.0 \%$ ( $>48-53 \mathrm{mmol} / \mathrm{mol})$. There was a slightly higher risk of VTE with increased HbA1c levels in women with CVD, but not in men.

Also in an analysis restricted to patients with a last HbA1c measurement within 90 days prior to the index date (Table 4), we only found a slight association between HbAlc levels $>7.0 \%$ ( $>53 \mathrm{mmol} / \mathrm{mol}$ ) and risk of VTE in women. The risk of VTE among women with a 90-day HbA1c level above $7.0 \%$ ( $>53 \mathrm{mmol} / \mathrm{mol})$ increased around $36-55 \%$ as compared to those with HbA1c levels $>6.5-7.0 \%$ ( $>48-53 \mathrm{mmol} / \mathrm{mol})$.

We found no association between the risk of VTE by HbA1c level in the group of patients with a T2DM duration of more than 5 years (Table 5 ). However, among patients with shorter T2DM duration ( $0-5$ years), those 
Table 1 Characteristics of the included cases and controls

\begin{tabular}{|c|c|c|c|c|}
\hline Characteristics & Number of cases (\%) & $\begin{array}{l}\text { Number of controls } \\
\text { (\%) }\end{array}$ & $\begin{array}{l}\text { Unadjusted ORs } \\
(95 \% \mathrm{Cl})\end{array}$ & $\begin{array}{l}\text { Adjusted ORs* } \\
(95 \% \mathrm{Cl})\end{array}$ \\
\hline \multicolumn{5}{|l|}{ Age (years) } \\
\hline$<60$ & $526(19.8)$ & $2112(19.9)$ & NA & NA \\
\hline $60-69$ & $570(21.5)$ & $2283(21.5)$ & NA & NA \\
\hline $70-79$ & $872(32.9)$ & $3500(33.0)$ & NA & NA \\
\hline $80+$ & $685(25.8)$ & $2717(25.6)$ & NA & NA \\
\hline \multicolumn{5}{|l|}{ Sex } \\
\hline Male & $1245(46.9)$ & $4980(46.9)$ & NA & NA \\
\hline Female & $1408(53.1)$ & $5632(53.1)$ & NA & NA \\
\hline \multicolumn{5}{|l|}{$\mathrm{BMI}\left(\mathrm{kg} / \mathrm{m}^{2}\right)$} \\
\hline$<18.5$ & $23(0.9)$ & $81(0.8)$ & $1.42(0.93-2.18)$ & $1.30(0.82-2.07)$ \\
\hline 18.5 to $<25.0$ & $340(12.8)$ & $1779(16.8)$ & 1 (reference) & 1 (reference) \\
\hline 25.0 to $<30.0$ & $770(29.0)$ & 3705 (34.9) & $1.12(0.99-1.28)$ & $1.15(1.01-1.31)$ \\
\hline 30.0 to $<35.0$ & $742(28.0)$ & $2823(26.6)$ & $1.47(1.28-1.68)$ & $1.46(1.28-1.67)$ \\
\hline 35.0 to $<40.0$ & $371(14.0)$ & $1208(11.4)$ & $1.80(1.54-2.11)$ & $1.72(1.47-2.02)$ \\
\hline$\geq 40.0$ & $343(12.9)$ & $749(7.1)$ & $2.82(2.39-3.34)$ & $2.65(2.24-3.15)$ \\
\hline Unknown & $64(2.4)$ & $267(2.5)$ & $1.26(0.96-1.67)$ & $1.30(0.95-1.79)$ \\
\hline \multicolumn{5}{|l|}{ Smoking status } \\
\hline Non-smoker & $1001(37.7)$ & $4301(40.5)$ & 1 (reference) & 1 (reference) \\
\hline Current smoker & $304(11.5)$ & $1257(11.9)$ & $1.04(0.91-1.19)$ & $1.00(0.87-1.14)$ \\
\hline Ex-smoker & $1312(49.5)$ & $4908(46.3)$ & $1.16(1.07-1.27)$ & $1.05(0.96-1.15)$ \\
\hline Unknown & $36(1.4)$ & $146(1.4)$ & $1.04(0.74-1.47)$ & $1.04(0.71-1.54)$ \\
\hline \multicolumn{5}{|c|}{ No. of $\mathrm{HbA1} \mathrm{c}$ measurements in the medical history before the index date } \\
\hline $1-4$ & $946(35.7)$ & $4006(37.8)$ & 1 (reference) & 1 (reference) \\
\hline $5-9$ & $1087(41.0)$ & $4375(41.2)$ & $1.06(0.96-1.19)$ & $1.06(0.95-1.19)$ \\
\hline 10 or more & $365(13.8)$ & $1343(12.7)$ & $1.19(1.02-1.40)$ & $1.06(0.90-1.26)$ \\
\hline No Recording & 255 (9.6) & $886(8.4)$ & $1.26(1.06-1.50)$ & $1.30(1.08-1.55)$ \\
\hline \multicolumn{5}{|l|}{ Comorbidities } \\
\hline Inflammatory bowel disease & $107(4.0)$ & $204(1.9)$ & $2.17(1.76-2.66)$ & $1.82(1.47-2.25)$ \\
\hline Chronic renal failure & $223(8.4)$ & $626(5.9)$ & $1.51(1.31-1.75)$ & $1.26(1.08-1.46)$ \\
\hline Diabetic retinopathy & $835(31.5)$ & $3090(29.1)$ & $1.17(1.07-1.29)$ & $1.20(1.08-1.32)$ \\
\hline Asthma & $564(21.3)$ & $1718(16.2)$ & $1.41(1.29-1.55)$ & $1.04(0.93-1.15)$ \\
\hline Congestive heart failure (CHF) & $315(11.9)$ & $712(6.7)$ & $1.93(1.71-2.19)$ & $1.53(1.34-1.76)$ \\
\hline Ischemic heart disease (IHD) & $690(26.0)$ & $2189(20.6)$ & $1.38(1.26-1.51)$ & $1.21(1.08-1.35)$ \\
\hline Myocardial infarction (MI) & $293(11.0)$ & $996(9.4)$ & $1.21(1.07-1.37)$ & $0.93(0.80-1.07)$ \\
\hline Stroke & $358(13.5)$ & $1220(11.5)$ & $1.21(1.08-1.35)$ & $1.19(1.05-1.34)$ \\
\hline Arterial hypertension & $1697(60.4)$ & $6866(64.7)$ & $0.97(0.89-1.05)$ & $0.93(0.85-1.01)$ \\
\hline Peripheral arterial disease & $139(5.2)$ & $340(3.2)$ & $1.68(1.41-2.01)$ & $1.52(1.26-1.84)$ \\
\hline Osteoarthritis & $985(37.1)$ & $3057(28.8)$ & $1.52(1.40-1.65)$ & $1.37(1.25-1.50)$ \\
\hline Rheumatoid arthritis & $94(3.5)$ & $226(2.1)$ & $1.69(1.37-2.08)$ & $1.29(1.03-1.62)$ \\
\hline Hyperlipidemia & $657(24.8)$ & $2640(24.9)$ & $0.99(0.91-1.09)$ & $0.91(0.83-1.00)$ \\
\hline Cardiovascular disease & $2033(76.6)$ & $7916(74.6)$ & $1.14(1.03-1.25)$ & $1.05(0.90-1.24)$ \\
\hline \multicolumn{5}{|l|}{ Co-medication ** } \\
\hline Insulin & $345(13.0)$ & $820(7.7)$ & $1.93(1.67-2.23)$ & $1.63(1.38-1.92)$ \\
\hline Glitazones & $367(13.8)$ & $1227(11.6)$ & $1.28(1.12-1.47)$ & $1.09(0.94-1.26)$ \\
\hline Sulfonylurea & 1009 (38.0) & 3651 (34.4) & $1.22(1.10-1.34)$ & $1.12(0.99-1.26)$ \\
\hline Metformin & $1621(61.1)$ & 6537 (61.6) & $0.97(0.88-1.07)$ & $0.64(0.41-1.01)$ \\
\hline GLP1 & $81(3.1)$ & $240(2.3)$ & $1.44(1.09-1.90)$ & $0.94(0.70-1.27)$ \\
\hline DPP4 & $224(8.4)$ & $926(8.7)$ & $0.96(0.81-1.13)$ & $0.84(0.71-1.00)$ \\
\hline SGLT2 & $43(1.6)$ & $170(1.6)$ & $1.01(0.71-1.46)$ & $0.99(0.68-1.44)$ \\
\hline
\end{tabular}


Table 1 (continued)

\begin{tabular}{lllll}
\hline Characteristics & Number of cases (\%) & $\begin{array}{l}\text { Number of controls } \\
(\%)\end{array}$ & $\begin{array}{l}\text { Unadjusted ORs } \\
\mathbf{( 9 5 \% ~ C l )}\end{array}$ & $\begin{array}{l}\text { Adjusted ORs* } \\
(\mathbf{9 5 \%} \text { Cl) }\end{array}$ \\
\hline All oral antidiabetics & $1814(68.4)$ & $7142(67.3)$ & $1.06(0.96-1.17)$ & $1.17(0.95-1.43)$ \\
Statins & $1941(73.2)$ & $8077(76.1)$ & $0.81(0.72-0.91)$ & $0.74(0.66-0.84)$ \\
Bisphosphonates & $340(12.8)$ & $850(8.0)$ & $1.79(1.55-2.06)$ & $1.49(1.28-1.74)$ \\
Contraceptive pill & $53(2.0)$ & $263(2.5)$ & $0.72(0.50-1.03)$ & $0.77(0.53-1.12)$ \\
Hormone replacement therapy & $392(14.8)$ & $1626(15.3)$ & $0.94(0.82-1.09)$ & $0.89(0.77-1.03)$ \\
Corticosteroids (systemic) & $975(36.8)$ & $2612(24.6)$ & $1.84(1.67-2.02)$ & $1.55(1.40-1.71)$ \\
Coronary vasodilators & $888(33.5)$ & $2797(26.4)$ & $1.43(1.30-1.57)$ & $1.22(1.07-1.39)$ \\
Low dose acetylsalicylic acid & $1556(58.7)$ & $5991(56.5)$ & $1.11(1.01-1.22)$ & $0.95(0.86-1.06)$ \\
Loop diuretics & $1152(43.4)$ & $2875(27.1)$ & $2.24(2.04-2.46)$ & $1.69(1.52-1.88)$ \\
All diuretics & $1854(69.9)$ & $6323(59.6)$ & $1.73(1.56-1.91)$ & $1.52(1.36-1.70)$ \\
\hline
\end{tabular}

*Adjusted for BMI (categorical), smoking (categorical), CHF, IHD, MI, stroke, hypertension, osteoarthritis, and use of insulin, bisphosphonate, systemic corticosteroids, low-dose acetylsalicylic acid, current and past use of metformin, and current and past use of sulfonylureas

**Use of other medication possible

Table 2 Risk of VTE by HbA1c level

\begin{tabular}{|c|c|c|c|c|}
\hline HbA1c-level & Number of cases (\%) & $\begin{array}{l}\text { Number of controls } \\
\text { (\%) }\end{array}$ & $\begin{array}{l}\text { Unadjusted ORs } \\
(95 \% \mathrm{Cl})\end{array}$ & $\begin{array}{l}\text { Adjusted ORs* } \\
(95 \% \mathrm{Cl})\end{array}$ \\
\hline \multicolumn{5}{|c|}{ HbA1c-Values (last measurement before the index date) and risk of VTE } \\
\hline$\leq 6.5 \%(\leq 48 \mathrm{mmol} / \mathrm{mol})$ & $843(31.8)$ & 3809 (35.9) & $0.98(0.87-1.10)$ & $0.98(0.87-1.10)$ \\
\hline$>6.5-7.0 \%(>48-53 \mathrm{mmol} / \mathrm{mol})$ & $441(16.6)$ & $1963(18.5)$ & 1 (reference) & 1 (reference) \\
\hline$>7.0-7.5 \%(>53-58 \mathrm{mmol} / \mathrm{mol})$ & $397(15.0)$ & $1522(14.3)$ & $1.17(1.02-1.34)$ & $1.13(0.98-1.30)$ \\
\hline$>7.5-8.0 \%(>58-64 \mathrm{mmol} / \mathrm{mol})$ & $208(7.8)$ & $839(7.9)$ & $1.13(0.95-1.33)$ & $1.09(0.92-1.29)$ \\
\hline$>8.0-9.0 \%(>64-75 \mathrm{mmol} / \mathrm{mol})$ & $253(9.5)$ & $834(7.9)$ & $1.38(1.18-1.61)$ & $1.30(1.10-1.52)$ \\
\hline$>9.0 \%(>75 \mathrm{mmol} / \mathrm{mol}))$ & $289(10.9)$ & $929(8.8)$ & $1.45(1.24-1.69)$ & $1.18(1.00-1.40)$ \\
\hline No Recording & $222(8.4)$ & $716(6.8)$ & $1.54(1.28-1.85)$ & $1.56(1.29-1.88)$ \\
\hline \multicolumn{5}{|c|}{ HbA1c-Values (last measurement before the index date) and risk of VTE in women } \\
\hline$\leq 6.5 \%(\leq 48 \mathrm{mmol} / \mathrm{mol})$ & $468(33.2)$ & $2106(37.4)$ & $1.04(0.89-1.22)$ & $1.05(0.89-1.23)$ \\
\hline$>6.5-7.0 \%(>48-53 \mathrm{mmol} / \mathrm{mol})$ & $220(15.6)$ & $1035(18.4)$ & 1 (reference) & 1 (reference) \\
\hline$>7.0-7.5 \%(>53-58 \mathrm{mmol} / \mathrm{mol})$ & $211(15.0)$ & $809(14.4)$ & $1.24(1.03-1.50)$ & $1.16(0.95-1.41)$ \\
\hline$>7.5-8.0 \%(>58-64 \mathrm{mmol} / \mathrm{mol})$ & $102(7.2)$ & $422(7.5)$ & $1.16(0.92-1.47)$ & $1.15(0.90-1.48)$ \\
\hline$>8.0-9.0 \%(>64-75 \mathrm{mmol} / \mathrm{mol})$ & $122(8.7)$ & $411(7.3)$ & $1.43(1.15-1.79)$ & $1.29(1.02-1.63)$ \\
\hline$>9.0 \%(>75 \mathrm{mmol} / \mathrm{mol}))$ & $154(10.9)$ & $456(8.10)$ & $1.68(1.36-2.09)$ & $1.36(1.07-1.72)$ \\
\hline No Recording & $131(9.3)$ & $393(7.0)$ & $1.81(1.42-2.31)$ & $1.87(1.46-2.40)$ \\
\hline \multicolumn{5}{|c|}{ HbA1c-Values (last measurement before the index date) and risk of VTE in men } \\
\hline$\leq 6.5 \%(\leq 48 \mathrm{mmol} / \mathrm{mol})$ & $375(30.1)$ & $1703(34.2)$ & $0.92(0.78-1.09)$ & $0.91(0.77-1.08)$ \\
\hline$>6.5-7.0 \%(>48-53 \mathrm{mmol} / \mathrm{mol})$ & $221(17.8)$ & $928(18.6)$ & 1 (reference) & 1 (reference) \\
\hline$>7.0-7.5 \%(>53-58 \mathrm{mmol} / \mathrm{mol})$ & $186(14.9)$ & $713(14.3)$ & $1.10(0.91-1.34)$ & $1.10(0.90-1.34)$ \\
\hline$>7.5-8.0 \%$ (> 58-64 mmol/mol) & $106(8.5)$ & $417(8.4)$ & $1.09(0.86-1.37)$ & $1.03(0.81-1.30)$ \\
\hline$>8.0-9.0 \%(>64-75 \mathrm{mmol} / \mathrm{mol})$ & $131(10.5)$ & $423(8.5)$ & $1.33(1.07-1.65)$ & $1.29(1.03-1.62)$ \\
\hline$>9.0 \%(>75 \mathrm{mmol} / \mathrm{mol}))$ & $135(10.8)$ & $473(9.5)$ & $1.24(0.99-1.55)$ & $1.03(0.81-1.30)$ \\
\hline No Recording & $91(7.3)$ & $323(6.5)$ & $1.26(0.95-1.66)$ & $1.24(0.93-1.66)$ \\
\hline
\end{tabular}

*Adjusted for BMI (categorical), smoking (categorical), CHF, IHD, MI, stroke, hypertension, osteoarthritis, and use of insulin, bisphosphonate, systemic corticosteroids, low-dose acetylsalicylic acid, current and past use of metformin, and current and past use of sulfonylureas

with HbA1c levels $>7.0 \%$ ( $>53 \mathrm{mmol} / \mathrm{mol}$ ) had slightly higher aORs for VTE when compared to T2DM patients with $\mathrm{HbA} 1 \mathrm{c}$ levels of $>6.5-7.0 \%$ (HbA1c $>7.0-7.5 \%$ : aOR
1.20, 95\% CI 0.97-1.49; HbA1c > 7.5-8.0\%: aOR 1.29, 95\% CI 1.00-1.67; HbA1c > 8.0-9.0\%: aOR 1.44, 95\% CI 1.131.83; HbA1c > 9.0\%: aOR 1.39, 95\% CI 1.07-1.79). 
Table 3 Risk of VTE according to HbA1c in patients with CVD

\begin{tabular}{|c|c|c|c|c|}
\hline Characteristics & Number of cases (\%) & Number of controls (\%) & $\begin{array}{l}\text { Unadjusted ORs } \\
(95 \% \mathrm{CI})\end{array}$ & $\begin{array}{l}\text { Adjusted ORs* } \\
(95 \% \mathrm{Cl})\end{array}$ \\
\hline \multicolumn{5}{|l|}{ CVD and risk of VTE } \\
\hline$\leq 6.5 \%$ & $670(33.0)$ & 2998 (37.9) & $0.99(0.87-1.13)$ & $1.01(0.89-1.15)$ \\
\hline$>6.5-7.0 \%$ & $352(17.3)$ & $1524(19.3)$ & 1 (reference) & 1 (reference) \\
\hline$>7.0-7.5 \%$ & $307(15.1)$ & $1142(14.4)$ & $1.19(1.02-1.39)$ & $1.14(0.97-1.34)$ \\
\hline$>7.5-8.0 \%$ & $163(8.0)$ & $610(7.7)$ & $1.18(0.98-1.43)$ & $1.13(0.93-1.38)$ \\
\hline$>8.0-9.0 \%$ & $193(9.5)$ & $568(7.2)$ & $1.49(1.24-1.78)$ & $1.39(1.16-1.68)$ \\
\hline$>9.0 \%$ & $201(9.9)$ & $624(7.9)$ & $1.47(1.22-1.77)$ & $1.16(0.95-1.42)$ \\
\hline No Recording & $147(7.2)$ & $450(5.7)$ & $1.55(1.25-1.94)$ & $1.56(1.24-1.96)$ \\
\hline \multicolumn{5}{|c|}{ HbA1c-Values (last measurement before the index date) and risk of VTE in women } \\
\hline$\leq 6.5 \%$ & $377(34.4)$ & $1689(39.2)$ & $1.04(0.87-1.23)$ & $1.07(0.90-1.28)$ \\
\hline$>6.5-7.0 \%$ & $177(16.2)$ & $818(19.0)$ & 1 (reference) & 1 (reference) \\
\hline$>7.0-7.5 \%$ & $166(15.2)$ & $618(14.4)$ & $1.29(1.04-1.59)$ & $1.21(0.96-1.51)$ \\
\hline$>7.5-8.0 \%$ & $87(7.9)$ & $317(7.4)$ & $1.30(1.00-1.69)$ & $1.26(0.95-1.66)$ \\
\hline$>8.0-9.0 \%$ & $93(8.5)$ & $285(6.6)$ & $1.39(1.08-1.80)$ & $1.30(0.99-1.70)$ \\
\hline$>9.0 \%$ & $107(9.8)$ & $318(7.4)$ & $1.64(1.28-2.12)$ & $1.27(0.97-1.68)$ \\
\hline No Recording & $89(8.1)$ & $260(6.0)$ & $1.80(1.35-2.41)$ & $1.83(1.35-2.46)$ \\
\hline \multicolumn{5}{|c|}{ HbA1c-Values (last measurement before the index date) and risk of VTE in men } \\
\hline$\leq 6.5 \%$ & $293(31.3)$ & $1309(36.3)$ & $0.94(0.78-1.14)$ & $0.94(0.78-1.13)$ \\
\hline$>6.5-7.0 \%$ & $175(18.7)$ & $706(19.6)$ & 1 (reference) & 1 (reference) \\
\hline$>7.0-7.5 \%$ & $141(15.1)$ & $524(14.5)$ & $1.09(0.87-1.37)$ & $1.06(0.84-1.34)$ \\
\hline$>7.5-8.0 \%$ & $76(8.1)$ & $293(8.1)$ & $1.07(0.82-1.41)$ & $0.98(0.74-1.31)$ \\
\hline$>8.0-9.0 \%$ & $100(10.7)$ & $283(7.8)$ & $1.59(1.23-2.05)$ & $1.50(1.15-1.96)$ \\
\hline$>9.0 \%$ & $94(10.0)$ & $306(8.5)$ & $1.30(0.99-1.72)$ & $1.06(0.79-1.41)$ \\
\hline No Recording & $58(6.2)$ & $190(5.3)$ & $1.26(0.90-1.78)$ & $1.26(0.88-1.81)$ \\
\hline
\end{tabular}

*Adjusted for BMI (categorical), smoking (categorical), CHF, IHD, MI, stroke, hypertension, osteoarthritis, and use of insulin, bisphosphonate, systemic corticosteroids, low-dose acetylsalicylic acid, current and past use of metformin, and current and past use of sulfonylureas

\section{Discussion}

In this large case-control study based on primary care data from the UK, patients with $\mathrm{HbA} 1 \mathrm{c}>7.0 \%$ ( $>53 \mathrm{mmol} / \mathrm{mol}$ ) did not have an increased risk of unprovoked VTE compared to patients with HbA1c $>6.5-7.0 \%$ (>48-53 mmol/mol). In the subset of female patients, we found a suggestion of a slightly increased risk of VTE in women with $\mathrm{HbA1c}>8.0 \%$ (for example $\mathrm{HbA1c}>8.0$ 9.0\%: aOR 1.29, 95\% CI 1.02-1.63) when compared to those with $\mathrm{HbA} 1 \mathrm{c}>6.5-7.0 \%$ ( $>48-53 \mathrm{mmol} / \mathrm{mol})$. This increase was slightly more pronounced if we only considered patients with $\mathrm{HbA1c}$ measurements taken within 90 days prior to the index date. Overall, however, the association in women was weak, and there was no trend of increasing risk of VTE in association with increasing HbA1c values. We did not observe an increased risk of VTE in men at any level of glycemic control.

The weak association between elevated $\mathrm{HbA1c}$ levels and risk of VTE in women, but not in men, may be explained by the fact that pre-diabetic and diabetic women are more affected by chronically elevated cardiovascular risk factors, and their health declines faster when compared to men. [22, 36, 37]. Since T2DM is a disease with uncertain onset, which can remain undiagnosed for many years, this difference in risk factor levels between men and women is relevant. Several studies, including a comprehensive meta-analysis, suggest that the presence of diabetes eliminates the biological female advantage that is often used to explain the lower absolute rates of coronary heart disease (CHD) and stroke in women compared to men [22, 38, 39]. The authors of this meta-analysis estimate that the relative risk for CHD is $44 \%$ greater in women with diabetes than in similarly affected men [39]. In general, our study population included more women than men, even though men are more often affected by T2DM and by VTE, when the diseases are observed independently of each other. The T2DM cohort for our study also included more men than women prior to the identification of the VTE cases (51.1\% vs $48.9 \%)$. Several studies provide an explanation for this imbalance in the rates of affected females and males by showing that adverse changes in metabolic and vascular risk factor profiles are greater in women than in men. These changes occur 
Table 4 Risk of VTE according to HbA1c levels measured within 90 days prior to the index date (i.d.)

\begin{tabular}{|c|c|c|c|c|}
\hline & Number of cases (\%) & Number of controls (\%) & $\begin{array}{l}\text { Unadjusted ORs } \\
(95 \% \mathrm{Cl})\end{array}$ & $\begin{array}{l}\text { Adjusted ORs* } \\
(95 \% \mathrm{Cl})\end{array}$ \\
\hline \multicolumn{5}{|c|}{$\mathrm{HbA} 1 \mathrm{c}$ level $<90$ days prior to i.d. overall } \\
\hline$\leq 6.5 \%$ & $278(22.9)$ & $1345(28.6)$ & $1.00(0.81-1.23)$ & $1.04(0.84-1.30)$ \\
\hline$>6.5-7.0 \%$ & $161(13.3)$ & $789(16.8)$ & 1 (reference) & 1 (reference) \\
\hline$>7.0-7.5 \%$ & $172(14.2)$ & $616(13.1)$ & $1.40(1.10-1.78)$ & $1.44(1.11-1.87)$ \\
\hline$>7.5-8.0 \%$ & $108(8.9)$ & $380(8.1)$ & $1.43(1.10-1.88)$ & $1.46(1.09-1.94)$ \\
\hline$>8.0-9.0 \%$ & $132(10.9)$ & $394(8.4)$ & $1.69(1.30-2.19)$ & $1.64(1.23-2.17)$ \\
\hline$>9.0 \%$ & $140(11.5)$ & $460(9.8)$ & $1.50(1.17-1.92)$ & $1.32(1.01-1.73)$ \\
\hline No Recording** & $222(18.3)$ & $716(15.2)$ & $1.75(1.36-2.23)$ & $1.78(1.38-2.31)$ \\
\hline \multicolumn{5}{|c|}{ HbA1c level $<90$ days prior to i.d. in women } \\
\hline$\leq 6.5 \%$ & $155(11.0)$ & $746(13.3)$ & $0.99(0.74-1.34)$ & $1.03(0.75-1.40)$ \\
\hline$>6.5-7.0 \%$ & $82(5.8)$ & $417(7.4)$ & 1 (reference) & 1 (reference) \\
\hline$>7.0-7.5 \%$ & $99(7.0)$ & $335(6.0)$ & $1.47(1.05-2.06)$ & $1.55(1.08-2.24)$ \\
\hline$>7.5-8.0 \%$ & $51(3.6)$ & $192(3.4)$ & $1.36(0.92-2.01)$ & $1.43(0.93-2.18)$ \\
\hline$>8.0-9.0 \%$ & $66(4.7)$ & $208(3.7)$ & $1.50(1.04-2.15)$ & $1.36(0.91-2.03)$ \\
\hline$>9.0 \%$ & $79(5.6)$ & $239(4.2)$ & $1.61(1.13-2.29)$ & $1.47(0.99-2.17)$ \\
\hline No Recording** & $876(62.2)$ & $3495(62.1)$ & $1.94(1.39-2.71)$ & $1.98(1.40-2.81)$ \\
\hline \multicolumn{5}{|c|}{$\mathrm{HbA} 1 \mathrm{c}$ level $<90$ days prior to i.d. in men } \\
\hline$\leq 6.5 \%$ & $125(10.0)$ & $614(12.3)$ & $1.00(0.75-1.34)$ & $1.04(0.76-1.43)$ \\
\hline$>6.5-7.0 \%$ & $81(6.5)$ & $379(7.6)$ & 1 (reference) & 1 (reference) \\
\hline$>7.0-7.5 \%$ & $76(6.1)$ & $292(5.9)$ & $1.32(0.93-1.86)$ & $1.35(0.91-1.99)$ \\
\hline$>7.5-8.0 \%$ & $58(4.7)$ & $191(3.8)$ & $1.50(1.04-2.17)$ & $1.48(0.99-2.22)$ \\
\hline$>8.0-9.0 \%$ & $67(5.4)$ & $186(3.7)$ & $1.93(1.33-2.80)$ & $1.94(1.28-2.96)$ \\
\hline$>9.0 \%$ & $62(5.0)$ & $226(4.5)$ & $1.37(0.96-1.95)$ & $1.23(0.83-1.82)$ \\
\hline No Recording ${ }^{* *}$ & $776(62.3)$ & $3092(62.1)$ & $1.50(1.04-2.17)$ & $1.56(1.04-2.34)$ \\
\hline
\end{tabular}

*Adjusted for BMI (categorical), smoking (categorical), CHF, IHD, MI, stroke, hypertension, osteoarthritis, and use of insulin, bisphosphonate, systemic corticosteroids, low-dose acetylsalicylic acid, current and past use of metformin, and current and past use of sulfonylureas

**Included are patients with missing $\mathrm{HbA} 1 \mathrm{c}$ measurements as well as those with a last $\mathrm{HbA} 1 \mathrm{c}$ level recorded $>90$ days prior to the index date

in diabetic individuals as well as earlier in pre-diabetic individuals [15, 22-24].

Patients with CVD and HbA1c levels $>7.0 \%$ (>53 mmol/ mol) did not have an increased risk of VTE when compared to those with HbA1c levels between $>6.5-7.0 \%$ (>48-53 $\mathrm{mmol} / \mathrm{mol}$ ), though women with CVD and HbA1c level > 7\% (>53 mmol/mol) had a slightly elevated risk for VTE, while men with CVD did not. This result emphasizes the general importance of proper glycemic control in women suffering from both, CVD and T2DM.

In our study, patients with no recorded HbAlc measurements had a higher risk of VTE compared to patients with $\mathrm{HbA1c}>6.5-7.0 \%$ (> $48-53 \mathrm{mmol} / \mathrm{mol})$ throughout our analyses. This could be a proxy for a lack of patientdoctor interaction and poor treatment adherence, which could lead not only to a higher risk for VTE (as suggested in this study), but potentially to other complications caused by improper management of T2DM. This assumption is reinforced by the results shown in Additional file 1: Supplementary Table 1, where patients without $\mathrm{HbA1c}$ measurements had much lower numbers for diagnosis of comorbidities, as well as for a corresponding prescription, when compared to patients who had at least 1 HbA1c measurement.

The present findings should be interpreted within the context of the strengths and limitations of an observational study. A delayed diagnosis of T2DM may have led to the inclusion of some prevalent (instead of incident) T2DM cases in our cohort. Additionally, the UK Prospective Diabetes study found that a high prevalence of DM tissue damage was already present by the time the DM diagnosis was made, which is an indication of pre-existing DM [40]. Therefore, we may have underestimated the time until VTE events (after the recorded DM diagnosis) in our study population, which could have potentially affected our matching on DM duration. However, this misclassification is unlikely to have been differential by HbA1c level, and we do not expect that it had a major influence on our findings.

Though VTE events are well recorded and have previously been validated in the CPRD (positive predictive value $88.2 \%$ [82.3-92.6\%] for VTE) [33], it is possible 
Table 5 Risk of VTE in patients with different T2DM durations

\begin{tabular}{|c|c|c|c|c|}
\hline & Number of cases (\%) & $\begin{array}{l}\text { Number of controls } \\
\text { (\%) }\end{array}$ & $\begin{array}{l}\text { Unadjusted ORs } \\
(95 \% \mathrm{Cl})\end{array}$ & $\begin{array}{l}\text { Adjusted ORs* } \\
(95 \% \mathrm{Cl})\end{array}$ \\
\hline \multicolumn{5}{|l|}{ Last $\mathrm{HbA1c:} 0-5$ y since T2DM diagnosis } \\
\hline$\leq 6.5 \%(\leq 48 \mathrm{mmol} / \mathrm{mol})$ & $446(33.7)$ & $2042(38.6)$ & $1.02(0.86-1.20)$ & $1.06(0.89-1.25)$ \\
\hline$>6.5-7.0 \%$ (> 48-53 mmol/mol) & $210(15.9)$ & $990(18.7)$ & 1 (reference) & 1 (reference) \\
\hline$>7.0-7.5 \%$ (>53-58 mmol/mol) & $172(13.0)$ & $651(12.3)$ & $1.24(1.01-1.51)$ & $1.20(0.97-1.49)$ \\
\hline$>7.5-8.0 \%$ (> 58-64 mmol/mol) & $86(6.5)$ & $326(6.2)$ & $1.30(1.01-1.68)$ & $1.29(1.00-1.67)$ \\
\hline$>8.0-9.0 \%$ (> 64-75 mmol/mol) & $104(7.9)$ & $336(6.4)$ & $1.51(1.20-1.91)$ & $1.44(1.13-1.83)$ \\
\hline$>9.0 \%(>75 \mathrm{mmol} / \mathrm{mol}))$ & $114(8.6)$ & $348(6.6)$ & $1.61(1.27-2.03)$ & $1.39(1.07-1.79)$ \\
\hline No Recording & $191(14.4)$ & $596(11.3)$ & $1.75(1.40-2.19)$ & $1.78(1.41-2.24)$ \\
\hline \multicolumn{5}{|c|}{ Last HbA1c: 5-10 y since T2DM diagnosis } \\
\hline$\leq 6.5 \%(\leq 48 \mathrm{mmol} / \mathrm{mol})$ & $260(32.1)$ & $1168(35.8)$ & $0.84(0.69-1.02)$ & $0.83(0.68-1.01)$ \\
\hline$>6.5-7.0 \%$ (> 48-53 mmol/mol) & $161(19.9)$ & $618(19.0)$ & 1 (reference) & 1 (reference) \\
\hline$>7.0-7.5 \%(>53-58 \mathrm{mmol} / \mathrm{mol})$ & $138(17.1)$ & $525(16.1)$ & $1.00(0.80-1.27)$ & $0.97(0.76-1.23)$ \\
\hline$>7.5-8.0 \%$ (> 58-64 mmol/mol) & $58(7.2)$ & $284(8.7)$ & $0.78(0.58-1.05)$ & $0.73(0.53-1.01)$ \\
\hline$>8.0-9.0 \%$ (> 64-75 mmol/mol) & $80(9.9)$ & $270(8.3)$ & $1.19(0.90-1.57)$ & $1.11(0.83-1.48)$ \\
\hline$>9.0 \%(>75 \mathrm{mmol} / \mathrm{mol}))$ & $85(10.5)$ & $306(9.4)$ & $1.07(0.81-1.40)$ & $0.87(0.65-1.16)$ \\
\hline No Recording & $27(3.3)$ & $88(2.7)$ & $1.24(0.81-1.91)$ & $1.46(0.93-2.31)$ \\
\hline \multicolumn{5}{|c|}{ Last $\mathrm{HbA} 1 \mathrm{c}:>10$ y since T2DM diagnosis } \\
\hline$\leq 6.5 \%(\leq 48 \mathrm{mmol} / \mathrm{mol})$ & $137(26.3)$ & $599(29.0)$ & $1.16(0.87-1.55)$ & $1.10(0.81-1.48)$ \\
\hline$>6.5-7.0 \%(>48-53 \mathrm{mmol} / \mathrm{mol})$ & $70(13.4)$ & $355(17.2)$ & 1 (reference) & 1 (reference) \\
\hline$>7.0-7.5 \%(>53-58 \mathrm{mmol} / \mathrm{mol})$ & $87(16.7)$ & $346(16.8)$ & $1.29(0.95-1.76)$ & $1.20(0.87-1.64)$ \\
\hline$>7.5-8.0 \%$ (> 58-64 mmol/mol) & $64(12.3)$ & $229(11.1)$ & $1.42(1.00-2.02)$ & $1.36(0.94-1.96)$ \\
\hline$>8.0-9.0 \%$ (> 64-75 mmol/mol) & $69(13.2)$ & $228(11.1)$ & $1.53(1.10-2.14)$ & $1.40(0.98-1.99)$ \\
\hline$>9.0 \%(>75 \mathrm{mmol} / \mathrm{mol}))$ & $90(17.3)$ & $275(13.3)$ & $1.74(1.26-2.40)$ & $1.33(0.92-1.91)$ \\
\hline No Recording & $4(0.8)$ & $32(1.6)$ & $0.56(0.23-1.37)$ & $0.58(0.22-1.52)$ \\
\hline
\end{tabular}

*Adjusted for BMI (categorical), smoking (categorical), CHF, IHD, MI, stroke, hypertension, osteoarthritis, and use of insulin, bisphosphonate, systemic corticosteroids, low-dose acetylsalicylic acid, current and past use of metformin, and current and past use of sulfonylureas

that we missed some unrecorded VTEs. This possible misclassification would likely be non-differential and would not materially change the results.

We considered BMI, previously diagnosed CVD, use of statins, as well as well as other factors that may increase the risk of VTE (see Table 1) in our analyses. However, we were not in the position to include data on diet, waist circumference, or physical activity, since this data is not available in the CPRD.

The strengths of our study include the large study sample and the observational nested case-control design within a cohort of patients with newly diagnosed T2DM. Our data come from a well validated primary care database that contains prospectively and routinely collected data, which avoids recall bias. Even though we only used the last HbA1c measurement before the index date, HbAlc measurements are regularly performed in the diabetic population, and median time between the index date and the last HbA1c measurement was short. This shows that the recorded HbA1c measurements provide a reliable and timely source for our analyses on the effect of glycemic control on the risk of VTE.

Our study population included a high proportion of patients with T2DM with $\mathrm{HbA1c} \leq 7 \%(>53 \mathrm{mmol} / \mathrm{mol})$ who may have been healthier than the T2DM populations analyzed in other studies. Nevertheless, our population consisted of over $13^{\prime} 000$ patients with T2DM, many of whom had HbA1c levels > 7\% (> $53 \mathrm{mmol} / \mathrm{mol}$ ). Therefore, we expect our results to be generalizable to those of other populations with T2DM and HbA1c levels > 7\% (>53 $\mathrm{mmol} / \mathrm{mol}$ ).

In conclusion, our study provides evidence that $\mathrm{HbA} 1 \mathrm{c}$ levels $>7 \%$ ( $>53 \mathrm{mmol} / \mathrm{mol}$ ) are not associated with a materially increased risk for unprovoked VTE overall. There was a suggestion of a slightly increased VTE risk in women, which may be real or may reflect differences in lifestyle or other patient characteristics.

\section{Conclusion}

Our study raises the possibility that female T2DM patients with HbA1c levels $>7 \%$ may have a slightly higher risk for unprovoked VTE compared to women 
with HbA1c level $>6.5-7.0 \%$. This increase may not be causal and may reflect differences in life style or other characteristics. We observed no effect of glycemic control on the risk of VTE in men.

\begin{abstract}
Abbreviations
aOR: Adjusted Odds Ratio; BMI: Body Mass Index; CHD: Coronary Heart Disease; CHF: Congestive Heart Failure; Cl: Confidence interval; CPRD: Clinical Practice Research Datalink; CVD: Cardiovascular disease; DM: Diabetes mellitus; DVT: Deep vein thrombosis; GFAT: Glutamine Fructose-6 Phosphate Amidotransferase; GP: General practitioner; HbA1c: Glycated hemoglobin A1c; HRT: Hormone replacement therapy; i.d.: Index date; IHD: Ischemic heart disease; ISAC: Independent Scientific Advisory Committee; MHRA: Medicines and Healthcare Products Regulatory Agency; MI: Myocardial infarction; NHS: National Health Services; NIHR: National Institute For Health Research; OAD: Oral antidiabetic drug; OR: Odds ratio; PE: Pulmonary embolism; UK: United Kingdom; T1DM: Type 1 diabetes mellitus; T2DM: Type 2 diabetes mellitus; VTE: Venous thromboembolism.
\end{abstract}

\section{Supplementary Information}

The online version contains supplementary material available at https://doi. org/10.1186/s12933-021-01432-1.

Additional file 1. Table S1. Characteristics of the included cases and controls without $\mathrm{HbA} 1 \mathrm{c}-$-measurement.

\section{Acknowledgements}

We thank Pascal Egger (Basel Pharmacoepidemiology Unit, University of Basel, Switzerland) for his technical support and programing. This study is based in part on data from the Clinical Practice Research Datalink obtained under licence from the UK Medicines and Healthcare Products Regulatory Agency. The data is provided by patients and collected by the NHS as part of their care and support. The interpretation and conclusions contained in this study are those of the authors alone.

\section{Authors' contributions}

Each of the named authors has substantially contributed to the preparation of this manuscript. All authors read and approved the final manuscript.

\section{Funding}

Not applicable.

\section{Availability of data and materials}

The data that support the findings of this study are available from the CPRD but restrictions apply to the availability of these data, which were used under license for the current study, and so are not publicly available. Data are however available from the authors upon reasonable request and with permission of CPRD.

\section{Declarations}

\section{Ethics approval and consent to participate}

The study protocol was approved by the Independent Scientific Advisory Committee (ISAC) for MHRA database research (protocol number 20_033) prior to the initiation of the study. The study protocol was made available to the journal reviewers.

\section{Consent for publication}

All of the authors have approved the contents of this paper and have agreed to the Cardiovascular Diabetology's submission policies.

\section{Competing interests}

We have no conflict of interest to declare, financial or otherwise.

\section{Author details}

${ }^{1}$ Basel Pharmacoepidemiology Unit, Division of Clinical Pharmacy and Epidemiology, Department of Pharmaceutical Sciences, University of Basel, Spitalstrasse 26, 4056 Basel, Switzerland. ${ }^{2}$ Hospital Pharmacy, University Hospital Basel, Basel, Switzerland. ${ }^{3}$ Division of Endocrinology, Diabetes \& Metabolism, University Hospital Basel, Basel, Switzerland. ${ }^{4}$ Boston Collaborative Drug Surveillance Program, Lexington, USA. ${ }^{5}$ School of Public Health, Boston University, Boston University School of Medicine, Lexington, USA.

Received: 10 September 2021 Accepted: 9 December 2021

Published online: 04 January 2022

\section{References}

1. Cho NH, et al. IDF Diabetes Atlas: Global estimates of diabetes prevalence for 2017 and projections for 2045. Diabetes Res Clin Pract. 2018;138:271-81.

2. The British Diabetic Association, Diabetes UK. Us, diabetes and a lot of facts and stats. [Fact sheet] 2019. Last accessed: [15.04.2021]. https://www. diabetes.org.uk/professionals/position-statements-reports/statistics.

3. Dokken BB. The pathophysiology of cardiovascular disease and diabetes: beyond blood pressure and lipids. Diabetes Spectrum. 2008;21 (3):160-5.

4. Carr ME. Diabetes mellitus: a hypercoagulable state. J Diabetes Complications. 2001;15(1):44-54.

5. National Institute for Health and Care Excellence (NICE). Venous thromboembolic diseases: diagnosis, management and thrombophilia testing (NG158). NICE Pathways, 2020.

6. Heit JA, et al. Is diabetes mellitus an independent risk factor for venous thromboembolism?: a population-based case-control study. Arterioscler Thromb Vasc Biol. 2009;29(9):1399-405.

7. Silverstein MD, et al. Trends in the incidence of deep vein thrombosis and pulmonary embolism: a 25-year population-based study. Arch Intern Med. 1998;158(6):585-93.

8. Essien E-O, Rali P, Mathai SC. Pulmonary embolism. Med Clin North Am. 2019;103(3):549-64

9. National Institute for Health and Care Excellence (NICE). Venous thromboembolic in adults: diagnosis and management (QS29). NICE Pathways, 2021. Last updated: [02.02.2021]. p. 5.

10. Martinez C, et al. Epidemiology of first and recurrent venous thromboembolism: a population-based cohort study in patients without active cancer. Thromb Haemost. 2014;112(2):255-63.

11. Engbers MJ, Vlieg A, Rosendaal FR. Venous thrombosis in the elderly: incidence, risk factors and risk groups. J Thrombosis Haemostasis. 2010;8(10):2105-12.

12. Tsai AW, et al. Cardiovascular risk factors and venous thromboembolism incidence: the longitudinal investigation of thromboembolism etiology. Arch Intern Med. 2002;162(10):1182-9.

13. Lemkes BA, et al. Hyperglycemia: a prothrombotic factor? J Thromb Haemost. 2010;8(8):1663-9.

14. Petrauskiene $V$, et al. The risk of venous thromboembolism is markedly elevated in patients with diabetes. Diabetologia. 2005;48(5):1017-21.

15. Evans RW, Orchard TJ. Oxidized lipids in insulin-dependent diabetes mellitus: a sex-diabetes interaction? Metabolism. 1994;43(9):1196-200.

16. Kentner AC, Grace SL. Between mind and heart: Sex-based cognitive bias in cardiovascular disease treatment. Front Neuroendocrinol. 2017:45:18-24

17. Selvin $\mathrm{E}$, et al. Glycated hemoglobin, diabetes, and cardiovascular risk in nondiabetic adults. N Engl J Med. 2010;362(9):800-11.

18. Fuller $\mathrm{JH}$, et al. Mortality from coronary heart disease and stroke in relation to degree of glycaemia: the Whitehall study. Br Med J (Clin Res Ed). 1983;287(6396):867-70

19. Bell EJ, et al. Glycemia (hemoglobin A1c) and incident venous thromboembolism in the Atherosclerosis Risk in Communities cohort study. Vasc Med. 2013;18(5):245-50.

20. Hermanides J, et al. Venous thrombosis is associated with hyperglycemia at diagnosis: a case-control study. J Thromb Haemost. 2009;7(6):945-9.

21. Lerstad $\mathrm{G}$, et al. Hyperglycemia, assessed according to $\mathrm{HbA1c}$, and future risk of venous thromboembolism: the Tromsø study. J Thromb Haemost. 2014;12(3):313-9. 
22. Appelman $Y$, et al. Sex differences in cardiovascular risk factors and disease prevention. Atherosclerosis. 2015;241(1):211-8.

23. Howard BV, et al. Adverse effects of diabetes on multiple cardiovascular disease risk factors in women: the strong heart study. Diabetes Care. 1998;21(8):1258-65.

24. Mansfield MW, Heywood DM, Grant PJ. Sex differences in coagulation and fibrinolysis in white subjects with non-insulin-dependent diabetes mellitus. Arterioscler Thromb Vasc Biol. 1996;16(1):160-4.

25. Laakso M. Heart in diabetes: a microvascular disease. Diabetes care. 2011;34(Suppl 2):S145-9.

26. Brownlee M. The pathobiology of diabetic complications. A Unifying Mechanism. 2005;54(6):1615-25.

27. Mathur R, et al. Completeness and usability of ethnicity data in UK-based primary care and hospital databases. J Public Health. 2013;36(4):684-92.

28. Herrett $E$, et al. Data resource profile: clinical practice research datalink (CPRD). Int J Epidemiol. 2015;44(3):827-36.

29. Jick H, Jick SS, Derby LE. Validation of information recorded on general practitioner based computerised data resource in the United Kingdom. BMJ. 1991;302(6779):766-8.

30. Jick SS, et al. Validity of the general practice research database. Pharmacotherapy. 2003;23(5):686-9.

31. Meier $C R$, et al. HMG-CoA reductase inhibitors and the risk of fractures. JAMA. 2000;283(24):3205-10.

32. Schlienger $R G$, et al. Use of $\beta$-blockers and risk of fractures. JAMA 2004;292(11):1326-32.

33. Khan NF, Harrison SE, Rose PW. Validity of diagnostic coding within the General Practice Research Database: a systematic review. Br J Gen Pract. 2010;60(572):e128-36.

34. Martín-Merino E, et al. Risk of venous thromboembolism among users of different anti-osteoporosis drugs: a population-based cohort analysis including over 200,000 participants from Spain and the UK. Osteoporos Int. 2018;29(2):467-78.

35. Ruigómez A, et al. Validation of venous thromboembolism diagnoses in patients receiving rivaroxaban or warfarin in The Health Improvement Network. Pharmacoepidemiol Drug Saf. 2021;30(2):229-36.

36. Donahue RP, et al. Sex differences in endothelial function markers before conversion to pre-diabetes: does the clock start ticking earlier among women? The Western New York Study. 2007:30(2):354-9.

37. Haffner SM, Miettinen H, Stern MP. Relatively more atherogenic coronary heart disease risk factors in prediabetic women than in prediabetic men. Diabetologia. 1997;40(6):711-7.

38. Huxley R, Barzi F, Woodward M. Excess risk of fatal coronary heart disease associated with diabetes in men and women: meta-analysis of 37 prospective cohort studies. BMJ. 2006;332(7533):73-8.

39. Peters SAE, Huxley RR, Woodward M. Diabetes as risk factor for incident coronary heart disease in women compared with men: a systematic review and meta-analysis of 64 cohorts including 858,507 individuals and 28,203 coronary events. Diabetologia. 2014;57(8):1542-51.

40. Group, U.P.D.S. UK prospective diabetes study xii: differences between Asian, Afro-Caribbean and white Caucasian type 2 diabetic patients at diagnosis of diabetes. Diabet Med. 1994;11(7):670-7.

\section{Publisher's Note}

Springer Nature remains neutral with regard to jurisdictional claims in published maps and institutional affiliations.

Ready to submit your research? Choose BMC and benefit from:

- fast, convenient online submission

- thorough peer review by experienced researchers in your field

- rapid publication on acceptance

- support for research data, including large and complex data types

- gold Open Access which fosters wider collaboration and increased citations

- maximum visibility for your research: over $100 \mathrm{M}$ website views per year

At BMC, research is always in progress.

Learn more biomedcentral.com/submissions 